\title{
The Challenge Against Economic Regulation Ethics Under the COVID-19 Epidemic: An Analysis of Unethical Behavior of Convenience
}

\author{
Jianguo Qu* \\ College of Education Science, Huaihua University, Huaihua, Hunan, China \\ *Corresponding Author.
}

\begin{abstract}
Purpose: Under the COVID-19 epidemic, public interest should be treated as a kind of public ethics. From the perspective of economic regulation, this study regards unethical behavior arising from the pursuit of convenience as a challenge against the public interest. It attempts to analyze the relationship between convenience and moral behavior from the perspectives of moral philosophy and psychology, reveal the factors influencing occurrence of unethical behavior of convenience, and express opinions on the construction of citizen morality under the epidemic. Method: By combining literature research and life cases, analysis is made on unethical behavior of convenience in life. Results: Convenience is a need in human moral life, and people may have unethical behaviors in the pursuit of convenience. The degree of convenience in the context of moral life, the clarity of moral clues, whether moral evasion is successful, and the tolerance of moral hazards are factors that affect whether individuals commit unethical behaviors in the pursuit of convenience. Conclusion: Respect for individual convenience is also respect for individual human rights, and overall convenience is the inherent requirement of social moral life. The epidemic has significantly impacted individual lives and public lifestyles. It is undoubtedly an important means to prevent and control the COVID-19 epidemic by regarding public interests as public ethics. For the need to jointly prevent and control the epidemic, it is recommended that schools incorporate convenience-related moral education content in light of the epidemic situation.
\end{abstract}

Keywords: Convenience, unethical behavior of convenience, economic regulation, ethics

\section{Background}

The COVID-19 epidemic is a sudden global public health event that has severely affected people's lifestyles on the planet. Given the spreading epidemic and unclear treatment, doing a good job in prevention and control is a guarantee of people's health. However, the need for prevention and control has brought many inconveniences to people's lives. For example, the government has issued many confinement orders, forcing a large number of people to stay at home. Nevertheless, this is undoubtedly a challenge to people's freedom, which will cause some controversy and even induce conflicts in some countries.

The reality tells us that during the epidemic, while doing a good job in medical and health care, we should also think about related ethical issues. From the perspective of economic regulation ethics, this paper analyzes and discusses the public ethics related to personal convenience and public interest, with a focus on the occurrence of unethical behaviors in individuals' pursuit of convenience, which is called unethical behavior of convenience in this research.

\section{Introduction to the Unethical Behavior of Convenience}

Unethical behavior of convenience is a concept opposite to unethical behavior whose subjective purpose is not to satisfy the subject's "convenience" needs. For example, crossing the grass may be a shortcut chosen to save time (convenience behavior), or it may be purely fun or lack of morality (non-convenience behavior). Convenience behavior of passing through grass which cannot be trampled under clear stipulation is unethical behavior of convenience. Simply put, the two major characteristics of convenient and unethical behavior are: (1) It is convenience-oriented behavior, or the subjective purpose of the behavior is to meet personal convenience needs; (2)

ISSN: 0010-8189

(C) CONVERTER 2021

www.converter-magazine.info 
The behavior substantially violates moral standards.

In contemporary social life, we often actively or passively receive news on some unethical behaviors of convenience -the behavior subject may deviate from the moral requirements or standards due to convenience requirements or for more convenience and easy achievement of certain goals. For example, convenient parking as an unethical incident is often posted and complained on the Internet. The Chongqing bus crashing incident in 2018 is a traffic tragedy caused by disputes owing to the passenger's requirement of stop out of personal convenience. Similarly, "in a scenario when you bypass the lawn to go to the library, if a path has been stepped out in the lawn, $22.4 \%$ students will definitely take shortcuts, and $64.8 \%$ students are uncertain about the choice." Such life scenarios are not uncommon. While bringing convenience to the public, the Internet also triggers a series of ethical issues, such as the frequently occurring Internet marketers, Internet water army, etc. [2]. Also, there are corruptions when one makes use of duty convenience. In the prevention and control of the COVID-19 epidemic, there are always people who seek their own convenience, reject wearing masks, refuse to take designated channels according to prevention and control regulations, and neglect others' dissuasion, leading to various disputes and conflicts. These indicate that people commit unethical behaviors from time to time in the pursuit of convenience.

\section{Convenience and Moral Life}

\subsection{Pursuit of convenience is a rational requirement of human behavioral economy}

Convenience means possibility to save time and energy for the behavior subject in the target activities [3]. To achieve greater benefit from or make optimal deployment and use of relatively limited resources, people regard certain convenience as a criterion or principle of choice and action in many situations [4]. It is inevitable that people are keen to solve the encountered life problems in a convenient way. Relevant studies have shown that customer convenience is an often noted aspect in consumer choice [5]. At the practical level, for example, provision of substantial "convenient" services under the guidance of facilitation theory to facilitate customers has been widely used nowadays as an important marketing strategy, and convenience stores in all corners provide a kind of powerful evidence.

Seen from the perspective of benefit optimization and maximization, people will inevitably pursue more convenience in life, which is a rational requirement of human behavioral economy. Therefore, although the increasingly perfect infrastructure, highly efficient transportation vehicles, and the virtual interaction of the E-net world have brought great convenience to people's lives today, people's desire for convenience is increasing steadily. The demand for convenience is growing day by day [6].

\subsection{Convenience is a need of human moral life}

Everyone has the right to pursue personal happiness, and of course, it also includes pursuit of more convenient life. The requirement for convenience is one of human rights claims, and respect for the convenience needs of others is viewed as an excellent quality. People believe that to help others is to help oneself.

Not only in our country, the principle of "convenience" is deemed as an official requirement of doing practical things for the people and improving people's livelihood. In handling of administrative affairs, it should see to it that people quickly and conveniently enjoy public cultural services. Relevant studies have shown that various facilities play different roles in the convenience of life. The convenience of life is one standard for livable cities proposed by the Chinese government." [7]. The "Singapore Criminal Code" makes separate stipulations in Chapter 14 on "crimes endangering public health, safety, convenience, etiquette and morality" [8]. It can be seen that convenience is a requirement for social moral life and also a content of the system. The pursuit of greater convenience should be considered as a manifestation of progress in social moral life.

3.3 The pursuit of convenience may induce unethical behavior

ISSN: 0010-8189

(C) CONVERTER 2021 
No matter who he is, the resources that can be occupied or mobilized by behavior subjects are always relatively limited. To reduce the cost of action, seeking "convenience" in problem solving is inevitable. A study indicates that although the government strongly advocates green travel among citizens, the urban transportation system itself is not convenient enough, so people will have lower willingness to choose public transportation. With it, the place is very likely to form a poor transportation structure highly dependent on car transportation [9]. As mentioned above, people will inevitably pursue greater convenience in life. We cannot deny it, nor can we deny the value of convenience based on sentiment or reason. If people over-consider "convenience" as a dimension and neglect the moral meaning in moral life, unethical behavior of convenience is very likely to occur.

\section{Factors Influencing Occurrence of Unethical Behavior of Convenience}

Speaking from the perspective of human moral self-confidence, we believe that almost no one is willing to do bad things from the beginning, nor one is willing to treat himself as immoral people. Our analysis of moral behavior should focus not only on understanding the starting point of behavior, but also on the mental activity process that constitutes moral behavior [10]. In other words, we should analyze both motivation and inducement; both internal causes and external causes.

\subsection{Convenience degree in moral life scenarios}

The subjective purpose of unethical behavior of convenience is to seek convenience. However, simply treating convenience as one's own self-interest, or ethically treating "convenience" as a concept opposite to "justice" [11], it is immoral itself and also a comical hypocrisy. Individual convenient parking has interfered with other people's normal lives, which is indeed very immoral and worthy of criticism, but how to plan and guide parking is more meaningful for the construction of social civic morality.

Anti-moral sentiment is often a reason for one's immoral behavior [12]. Inconvenient situations often cause emotional problems for the behavior subject, and even aggravate some anti-moral emotions. People sometimes cannot understand why there are so many obstacles and so many restrictions? It is similar to prove that "I am myself, my father is my father". For many people, it is a kind of superfluous boredom. Inconvenience in the context of moral life has increased the probability of unethical behavior of convenience.

\subsection{Clarity of moral clues in the scenario}

Human behavior is the product of interaction between external environmental cues and internal factors. Studies have found that the clearer the moral warnings in the scenarios is, the clearer the individual's moral concepts is, which in turn inhibits unethical behavior [13]. This is exactly the same as the principle that "anything is viable without law prohibition". Grasslands with moral warning signs are often far less damaged than those without any instructions.

If the moral clues are not clear enough, then it is possible that "you didn't say, I don't know", or "I" can pretend not to know. Those who don't know are not guilty, or they are not so guilty. It is just a small mistake, and it doesn't hurt the important essentials. With such psychology, in a specific situation that requires more convenience, not only unethical behavior of convenience will have significantly increased occurrence probability, but also one will easily follow the crowd.

\subsection{The possibility of moral evasion}

Moral beliefs and power reflect the greatness of human beings, "even if an individual knows that he has some bad traits, he will firmly believe that his inner self is moral" [14]. No matter what kind of moral behavior we commit, we need a reason to convince ourselves. Moral evasion is one of the reasons why normal people conduct immoral behavior without self-accusation [15].

In unethical behavior incidents of convenience, the behavior subject will usually take "urgent expediency" as a

ISSN: 0010-8189

C CONVERTER 2021

Www.converter-magazine.info 
rational explanation to reduce the sense of moral guilt. Picking up children from school is always more important than illegal parking. Through dispersion of responsibilities and attribution of blame, individuals easily have moral excuses for unethical behavior of convenience. For example, there may be moral excuses for unethical convenient parking like "I am not the only one, everyone parks like this", "Why there is no reservation of more parking spaces in crowded public places like schools and hospitals?"

\subsection{Tolerability of moral hazard assessment}

Although subjects of unethical behavior of convenience have subjectively rationalized their possible actions with moral excuses, they do not completely deny their due responsibilities and moral obligations. That is, in fact, in many circumstances, they know that they are the "incorrect person", and they also know that unethical behavior will be punished and morally condemned accordingly.

Drawing on advantages and avoiding disadvantages is an instinct of almost all living creatures. Before actions, normal people will first weigh the pros and cons, gains and losses in mind. Therefore, individuals will weigh the moral pros and cons before making a moral action decision, and will evaluate the moral hazard brought by his personal behavior. If individual's convenience appeal can be rationalized in moral perception and the psychological cost or moral hazard brought by the behavior is evaluated as extremely low, then the convenience challenge against morality will have a high probability of victory. It is just like a one-hundred-yuan fine for illegal parking. In the range tolerable for many people, coupled with some fluke psychology, convenient parking is not uncommon. Tolerable moral hazard assessment may be the last straw that overwhelms individual moral beliefs, which is a further reasonable and justifiable reinforcement of unethical behavior of convenience.

\section{Discussion: Citizens' Moral Construction from the Perspective of Unethical Behavior of Convenience under Epidemic}

5.1 Build a convenient living environment to promote the development of citizens' moral life

The solution to moral problems is not entirely within the scope of morality, and forces or measures beyond morality are indispensable [16]. For instance, before the appearance of urban public parking lot, people were not allowed to park on the roadside, so there were no reasonable alternative, which forces people to make the unique moral choice and deviates from the moral spirit in logical sense. It is the existence of some inconveniences in life that make people sense the value of convenience more and more. In turn, feelings of incomprehension, complaint and even hatred of inconvenience appear. If we proceed from the perspective of serving and caring for the people, reach the community and family in work, strengthen communication and cooperation in all aspects, and build a convenient living environment, these will surely promote the development of civic moral life and objectively benefit the construction of civic morality.

During the epidemic, the need for prevention and control has caused more inconvenience to people's travel. Objectively speaking, it is almost impossible to create absolutely convenient living conditions, but relative transformation or improvement can also be described as endless. In construction of a convenient living environment, top-down macro-control is indispensable, but acquisition of real convenience demand information by bottom-up approach is all the more important. In Times of emergency, such as epidemics, it is all the more necessary to provide adequate security and at least adequate care for the well-being of people.

5.2 Develop individual rational moral emotions of convenience to increase moral coordination awareness of convenience

Many people can have intuitive ethical discomfort towards immoral behavior in life scenarios, but they may find it impossible to answer what is "wrong". When one interferes with the driver amid movement of the vehicle, it is difficult to say that the person concerned is clearly aware of the dangers of such actions and the illegality of the behavior; when one blocks the door for private ends, it is also difficult to say that the person concerned is aware that

ISSN: 0010-8189

(C) CONVERTER 2021

Www.converter-magazine.info 
her behavior is illegal and is very likely to cause the paralysis of the entire railway system, even causing a major traffic accident (the female teacher involved felt very "wronged": "I did not stop the car, I am just a person, how can I stand in front of the train to stop it from driving) .

Unethical behavior often reveals the shallow moral cognition of the individual. Without sufficient moral knowledge and awareness of rules, one will have no rational concept of "convenience", and therefore no corresponding rational moral emotions. One will then be unable to aware the social value of "inconvenience" in these situations, let alone actively coordinate personal convenience with overall convenience. The results of the COVID-19 epidemic suggest that many people are unaware of the danger of this new epidemic, and refuse to wear masks in pursuit of personal convenience, missing many opportunities of avoiding cross-interference. In fact, related studies have shown that wearing masks in the community may reduce the emission of saliva and respiratory droplets in patients with subclinical or mild COVID-19, thereby helping to control COVID-19 [17].

Rosenblum [18] believes that every adult should be able to make many unhappy or unfavorable effective decisions in view of many aspects of his or her life, because these decisions match the freedom of every other adult. Ability to make a decision that meets the requirements of moral values must be supported by rich moral cognition and corresponding strong rational moral emotions. One must be able to distinguish the good from the bad, and feel the correlation between one's emotions and others' emotions.

5.3 Improve citizens' awareness of the risks of unethical behavior of convenience to inhibit the occurrence of unethical behaviors

Past moral behavior has an impact on future moral behavior. A considerable part of the basis of moral hazard assessment derives from the information feedback of others or society on one's moral behavior, especially whether there is education and punishment. Such information plays a role in direct or vicarious reinforcement. In moral life, if an individual's unethical behavior is not duly condemned or punished in a timely manner, the plain information feedback is insufficient to change one's moral concepts, let alone develop moral beliefs. If the moral subject does not regard obligation as the highest motivation for behavior, and does not perform the obligation with "the belief in the obligation", then the meaning and value of conscience in behavior will be degraded [19].

Without sufficient moral beliefs, the temptation of convenience will be particularly strong, especially in a depersonalized context. Regarding the implementation of unethical behavior for convenience, if the benefits are considerable with small cost, it will make relevant personnel divert their energy to unethical behavior [20]. People with lower assessment of moral hazard are more likely to induce unethical behavior. Studies have pointed out that the Covid-19 pandemic exerts shocking effects on individual and collective health, as well as emotional and social functions [21]. People's acceptance of large-scale closure orders needs to be based on the awareness of the social harm and moral hazard as a result of individual disobedience.

\section{Conclusion}

Occurrence of unethical behavior of convenience has relation to the moral beliefs in the individual's heart, but if you blindly criticize the moral quality of the behavior subject, it will inevitably lead to moral kidnapping. It must be admitted that convenient life conforms to the rational requirements of behavioral economy, respect for individual convenience is also respect for individual human rights, and overall convenience is the inherent requirement of social moral life. However, during the epidemic, people will undoubtedly strengthen the emphasis on public interest and regard public interest as public ethics, which is no doubt one important means for the prevention and control of the COVID-19 epidemic.

Some approaches of epidemic prevention and control have caused many inconveniences to people's lives. The epidemic has caused a major impact on people's individual and collective lives. The conflict between individual convenience and public interest brought about by the epidemic triggers more thinking about public ethics. It is

ISSN: 0010-8189

(c) CONVERTER 2021

www.converter-magazine.info 
necessary for school education to appropriately introduce moral education content of convenience based on the epidemic and its prevention and control. Unethical behavior of convenience requires criticism, but it also requires some understanding that it is not simply the result of a person's moral convictions. The mutual understanding and unity of people will build a favorable protective wall against the epidemic.

\section{References}

[1] J. L. Zhu, "The status quo of college students' civilized training and the study of educational countermeasures - take Hangzhou University as an example," Teaching and Educating (Higher Education Forum), 2018.

[2] F. Ma, W. X. Wang, "Spreading network rumors under the sociological field of view multi-dimensional prevention and control path," Journal of Chongqing University of Posts and Telecommunications (SocialSciences Edition), no. 11, pp. 73-79, 2018.

[3] P. Gottschalk, "Convenience in white-collar crime: Introducing a core concept," Deviant Behavior, vol. 38, no. 5, pp. 605-619, 2017.

[4] C. L. D. Tj, M. L. Radford, "Convenience as a critical factor in information-seeking behaviors," Library and Information Science Research, vol, 33, no. 3, pp.179-190, 2011.

[5] J. D. Farquhar, J. Rowley, “Convenience: a services perspective,” Marketing Theory, vol. 9, no. 4, pp. 425438, 2009.

[6] L. L. Berry, K. Seiders, D. Grewal, "Understanding service convenience,” Journal of marketing, vol. 66, no. 3, pp. 1-17, 2002.

[7] X. Zhang, S. Du, J. Zhang, "How do people understand convenience-of-living in cities? A multiscale geographic investigation in Beijing," ISPRS Journal of Photogrammetry and Remote Sensing, vol. 148, pp. 87-102, 2019.

[8] Y. Gao, "Misdemeanor theory," Heilongjiang University, 2018.

[9] H. Wang, J. J. Huang, Y. L. Li, et al, "Analysis of urban space travel convenience and car dependence in Xiamen,” Acta Geographica Sinica, vol. 68, no. 4, pp. 477-490, 2013.

[10] W. Zhang, W. G. Yang, "Changes from DIT to ICM: ethical judgment tests," Journal of Education, no. 4, pp. 98-104, 2017.

[11] Mill, “Translated by Liu Fusheng, utilitarian IMI,” Beijing: Guangming Daily Press, 2007.

[12] Y. M. Li, "Emotional biomedical intervention and moral enhancement," Natural dialectics research, no. 8, pp. 3, 2018.

[13] F. Gino, S. Ayal, D. Ariely, "Contagion and differentiation in unethical behavior: the effect of one bad apple on the barrel," Psychological Science, vol. 20, no. 3, pp. 393-398, 2009.

[14] X. J. Yang, Y. X. Zhang, X. Lei, "Moral self-evaluation after the on generation of unethical behavior. Chinese Journal of Health Psychology, no. 2, pp. 235-239, 2016.

[15] L. C. An, S. C. Zhang, H. Wang, et al., "Effects of co-influence on college students' pros social behavior: the multiple intermediary effects of moral push and guilt," Psychology, vol. 38, no. 4, pp. 350-355, 2018.

[16] Z. Z. Du, "How does the system yudde?" Journal of Central China Normal University: Humanities and Social Sciences Edition, vol. 51, no. 4, pp. 126-131, 2012.

[17] V. C. C. Cheng, S. C. Wong, V. W. M. Chuang, et al., "The role of community-wide wearing of face mask for control of coronavirus disease 2019 (COVID-19) epidemic due to SARS-CoV-2," Journal of Infection, vol. 81, no. 1, pp. 107-114, 2020.

[18] N. L. Rosenblum, “Liberalism and the moral life," Cambridge, MA: Harvard University Press, 1989.

[19] Y. M. Chen, "On the significance of Hegel's conscience to the moral construction of our citizens," Industry and Technology Forum, no. 22, pp. 59, 2018.

[20] X. Q. Qi, "PMC model for the study of ethical risk faced by owners," Master's Thesis, University of Western China, 2018.

[21] B. Pfefferbaum, C. S. North, "Mental health and the Covid-19 pandemic," New England Journal of Medicine, vol. 383, no. 6, pp. 510-512, 2020.

ISSN: 0010-8189 